\title{
Implications of Climate Change on Vector and Vector-Borne Parasitic Diseases: A Bird's Eye View
}

\author{
Savita Bisen $^{1 *}$, Nidhi Rawat ${ }^{2}$, Namrata Wahane ${ }^{1}$ and Pradeep Dubey ${ }^{3}$ \\ ${ }^{1}$ Department of Veterinary Parasitology, College of Veterinary Science and A.H., \\ Anjora, Durg, Chhattisgarh, India \\ ${ }^{2}$ Department of Veterinary Microbiology, College of Veterinary Science and A.H., \\ Anjora, Durg, Chhattisgarh, India \\ ${ }^{3}$ Department of Veterinary Pathology, College of Veterinary Science and A.H., \\ Anjora, Durg, Chhattisgarh, India \\ *Corresponding author
}

K e y w o r d s
Climate change,
Vector, Vector-
borne parasitic
diseases, Global
warming, Remote-
sensing, Geographic
information system
(GIS)
Article Info
Accepted:
15 February 2020
Available Online:
10 March 2020

\section{A B S T R A C T}

Global climate change and increased climate variability are particularly likely to affect vector and vector-borne parasitic diseases. Climate change will affect the distribution and incidence of vector-borne parasitic diseases globally. Climate change, particularly global warming, is already altering habitat quality, species distributions, biodiversity and many essential ecosystem services. Arthropods are highly sensitive to changes in temperature and precipitation as they cannot regulate their own internal temperatures and are therefore critically dependent on climate for survival and development. Vector-borne diseases (VBDs) are among the major causes of morbidity and mortality in the world today affecting nearly half of the world's population, the majority of who reside in developing countries located in the tropical and subtropical areas of the world. Improved surveillance and monitoring is needed so as to detect changes resulting from global climate and ecological change, both for the identification of immediately required action and to serve as the basis for developing predictive models. Predicting how the longterm distribution and prevalence of such important human and animal diseases will change in the face of global warming is a key challenge facing humans in the near future.

\section{Introduction}

There are both direct and indirect implications of climate change on the scope and distribution of parasitic organisms and their associated vectors and host species. The definition provided by UNFCCC (United Nations Framework Convention on Climate Change) describes climate change as "a change of climate which is attributed directly 
or indirectly to human activity that alters the composition of the global atmosphere and which is in addition to natural climate variability observed over comparable time periods" (IPCC, 2012). The climatic change is evidenced by the manifestations like increase in mean surface temperature, increase in sea surface temperature, varying patterns in precipitation, glacier melt down/retreat, sea level increase, frequent floods and droughts, cyclonic storms, coastal erosion, biodiversity loss, increased El-Nino events etc.

Climate change may be attributed to natural internal processes or external forcing or to persistent anthropogenic activities. These include natural factors, such as changes in the sun's intensity or slow changes in the Earth's orbit around the sun; various natural phenomenons like volcanic eruptions, tectonic disturbances, ENSO (EL NINO Southern Oscillation), North Atlantic Oscillations etc. and human activities that change the atmosphere's composition (e.g. through burning fossil fuels) and the land surface (e.g. deforestation, reforestation, urbanization, desertification, etc.).

In order to understand why global climate change is occurring, let's first understand what occurs in the earth's atmosphere. The earth's atmosphere consists mainly of nitrogen and oxygen, with small amount of hydrogen, helium, argon, neon and other gases. A greenhouse gas is a gas that traps infrared energy (heat) in the atmosphere.

Carbon dioxide, $\mathrm{CO}_{2}$ (sources: fossil fuel combustion and land use changes), Methane, $\mathrm{CH} 4$ (sources: arable farming and livestock production), Nitrous oxide, $\mathrm{N}_{2} \mathrm{O}$ (sources: fertilizer use and fossil fuel combustion) and CFC-12 and CFC-11 (sources: propellants and solvents) are major greenhouse gases. The terrestrial biosphere can release or absorb the greenhouse gases, carbon dioxide $\left(\mathrm{CO}_{2}\right)$, methane $\left(\mathrm{CH}_{4}\right)$ and nitrous oxide $\left(\mathrm{N}_{2} \mathrm{O}\right)$ and therefore has an important role in regulating atmospheric composition and climate (Tian et al., 2016). The relative heat trapping ability (in $\mathrm{CO}_{2}$ equivalent) of $\mathrm{CO}_{2}, \mathrm{CH} 4, \mathrm{~N}_{2} \mathrm{O}$ and CFC are 1, 23, 296, and 12,000 respectively (IPCC, 2001). The sources of global atmospheric concentrations of $\mathrm{CO}_{2}$ percentage from burning of fossil fuels is $49 \%$, industrial process $24 \%$, deforestation $14 \%$ and agriculture $13 \%$. Global atmospheric concentrations of $\mathrm{CO}_{2}, \mathrm{CH} 4$ and $\mathrm{N}_{2} \mathrm{O}$ have increased markedly as a result of human activities since 1750 and now far exceed preindustrial values determined from ice cores spanning many thousands of years.

According to WMO Greenhouse Gas Bulletin, concentrations of carbon dioxide have increased from $280 \mathrm{ppm}$ (pre-industrial value) to $405.5 \mathrm{ppm}$ in 2017, $\mathrm{CH} 4$ from 700 ppb to $1859 \mathrm{ppb}$ in 2017, $\mathrm{N}_{2} \mathrm{O}$ from $270 \mathrm{ppb}$ to $329.9 \mathrm{ppb}$ in 2017 , CFC-11 from 0 to 241 ppt in 2016. So the Carbon dioxide $\left(\mathrm{CO}_{2}\right)$, methane $(\mathrm{CH} 4)$, nitrous oxide $\left(\mathrm{N}_{2} \mathrm{O}\right), \mathrm{CFC}-12$ and CFC-11 are considered to be the major greenhouse gases that are continuously increasing in concentration since 1978.

Most of the observed increase in global average temperatures since the mid-20th century is very likely due to the observed increase in anthropogenic GHG concentrations. The IPCC predicted that by around 2100 global temperatures will have risen by between 1.1 and $6.4^{\circ} \mathrm{C}$ and in the course of the present century sea levels will rise by between 18 and 59 centimetres (IPCC, 2007).

The overall effects of global climate change are likely to be harmful. Humans and animals could suffer from increased spread of infectious diseases, heat related deaths and air pollution. Global climate change and increased climatic variability are particularly 
likely to affect water and vector borne parasitic diseases. Temperature, precipitation, humidity and other climatic factors are known to affect the reproduction, development, behaviour and population dynamics of the arthropod vectors of these diseases.

Climate variables are also able to affect the prevalence, intensity and geographical distribution of helminthes, directly influencing free-living larval stages and indirectly influencing mainly invertebrate, but also vertebrate hosts (Mas-Coma et al., 2009).

\section{Impact of global climate change on vector- borne parasitic diseases}

VBDs are diseases that are spread by arthropod or small animal vectors. Vectorborne diseases (VBDs) are among the major microbial causes of morbidity and mortality in the world today affecting nearly half of the world's population, the majority of who reside in developing countries located in the tropical and subtropical areas of the world.

In countries that provide statistics to the WHO, VBDs collectively account for more than 1.5 million human deaths per year (Hill et al., 2005). However, many diseases are under-reported, especially those that are rarely fatal like Onchocerciosis and Lymphatic filariasis. The geographical distribution of VBDs is largely reflective of the geographical distribution of both vectors and their reservoir hosts (if they have reservoir hosts).

Vectors act as the main mode of transmission of infection from one host to another and as such constitute an essential stage in the transmission cycle. Two main types of VBD transmission exist: Anthroponotic infections or human-vector-human transmissions, where humans are the only reservoir of the disease.

Zoonotic infections or animal-vector-human transmission, where animals are the main reservoir of the disease and humans are considered secondary or spillover hosts and do not generally contribute to the disease transmission cycle as their levels of circulating pathogen are often too low to help maintain transmission.

The type of transmission of a VBD has implications for control strategies. Anthroponotic infections can theoretically be eradicated if all human cases of the disease can be treated, whereas zoonotic diseases are much more difficult to control since all animal reservoirs of the disease would need to be treated.

\section{Vector-borne disease dynamics}

There are 3 crucial elements which must coexist for the occurrence of VBD: the susceptible population, the vector (most often arthropods), and the disease pathogen (e.g., bacteria, virus, parasite).

In areas where VBD most frequently occurs, conditions must be suitable for vectors and pathogens, which imply physiologically suitable conditions for vector, host and pathogen survival and reproduction/replication. Global climate change is likely to affect all 3 of these components both directly and indirectly.

As an example of direct effects: Arthropods are highly sensitive to changes in temperature and precipitation as they cannot regulate their own internal temperatures and are therefore critically dependent on climate for survival and development (Githeko et al., 2000). Changes in climate may accelerate the development time of some arthropod species.

Similarly, many pathogens are climate sensitive as well and changes in climate could result in increased reproduction rates of some pathogens. Example of indirect effects might 
include: Changes in livelihood conditions due to climate change which could affect nutritional status of individuals, thereby potentially increasing susceptibility to disease.

\section{Direct effects of climate change on vector-} borne diseases

Climate change has the potential to:-

Increase range or abundance of animal reservoirs and/or arthropod vectors (e.g., Malaria, Schistosomiosis)

Enhance transmission (e.g., West Nile virus and other arboviruses).

Increase importation of vectors or pathogens (e.g., Dengue, Chikungunya,).

Increase animal disease risk and potential human risk (e.g., African trypanosomiasis) (Greer et al., 2008).

Effect of temperature on vectors and pathogens

\section{Vector}

Survival can decrease or increase depending on species.

Some vectors have higher survival at higher latitudes and altitudes with higher temperatures.

Changes in the susceptibility of vectors to some pathogens e.g. higher temperatures reduce size of some vectors but reduce activity of others.

Changes in the rate of vector population growth.

Changes in feeding rate and host contact (may alter survival rate).

Changes in seasonality of populations.

\section{Pathogen}

Decreased extrinsic incubation period of pathogen in vector at higher temperatures.

Changes in transmission season.

Changes in distribution.

\section{Effects of changes in precipitation on} vector and vector-borne pathogens

\section{Vector}

Increased rain may increase larval habitat and vector population size by creating new habitat.

Excess rain or snowpack can eliminate habitat by flooding, decreasing vector population.

Low rainfall can create habitat by causing rivers to dry into pools (dry season malaria).

Decreased rain can increase containerbreeding mosquitoes by forcing increased water storage.

Epic rainfall events can synchronize vector host-seeking and virus transmission.

Increased humidity increases vector survival; decreased humidity decreases vector survival.

\section{Pathogen}

Few direct effects but some data on humidity effects on malaria parasite development in the anopheline mosquito host is available.

Increased sea level effects on selected vector-borne pathogens

Alters estuary flow and changes existing salt marshes and associated mosquito species, decreasing or eliminating selected mosquito breeding-sites (e.g. reduced habitat for Culiseta melanura) (Gubler, 2001).

\section{Vector activity}

Vector activity is significantly affected by humidity and precipitation. A greater relative humidity can increase vector 
activity, but heavy rainfall can actually decrease activity.

Increased activity increases transmission rates.

\section{Vector survival}

Mortality rates increase at high and low temperatures. Temperature effects on development may affect mortality rates: particularly high rates of development of mosquitoes can result in small adults with poorer survival. This is one example where the terms in epidemiological models of VBDs interact with one another.

Another important interaction is the dependence of transmission coefficients for tick-borne pathogens on the numbers of vectors feeding on the host. High "monsoon" rainfall knocks ticks off the herbage and prevents them from finding a host. Lower humidity increase the energy requirement for host seeking by ticks thereby shortening their lives. Lower rainfall decrease breeding areas for mosquitoes and it is compounded by density-dependent intraspecific competition amongst larvae.

\section{Vector and host seasonality}

Many VBDs are zoonotic and have life cycles that are fully maintained in wildlife. In these diseases, seasons often play a very important role in the relationships between vectors and hosts. Both vectors and hosts have seasonal variations in their life cycles driven by seasonal changes in climate and climate independent effects such as day length. Vectors can be affected by the way in which temperature can change from season to season with resultant impacts on their development, activity and disease transmission role. The lifecycle and activity level of the host can be affected as well, affecting how fast infected or immune animals die and how fast uninfected animals are borne, with resultant impacts on the epidemiology of vector-borne zoonoses.

There are many vector-borne parasitic diseases of concern, especially in developing countries, a number of which are on the WHO list of neglected tropical diseases (including Leishmaniosis, Trypanosomiosis, Chagas, Lymphatic filariasis, and Onchocerciosis) because they occur in areas where poverty is the most significant risk factor for their occurrence.

\section{Malaria}

Approximately $40 \%$ of the world's population lives in areas at risk for malaria. Globally, an estimated 3.4 billion people in 92 countries are at risk of being infected with malaria and developing disease and 1.1 billion are at high risk. According to World Malaria Report (2019), there were 228 million cases of malaria globally in 2018 and 405000 malaria deaths. Mostly children aged less than 5 years in sub-Saharan Africa die each year of malaria. While most of the increase is predicted to occur in Africa, some increased risk is projected in Britain, Australia and Portugal. IPCC (2012) predicts that the global population at risk for malaria will increase by 220-400 million in the next century.

Malaria is an extremely climate sensitive disease. Transmission does not occur in climates where mosquitoes cannot survive. Optimal larval development occurs at $28^{\circ} \mathrm{C}$ and optimal adult development between 28 and $32^{\circ} \mathrm{C}$. Transmission cannot occur below $16^{\circ} \mathrm{C}$ or above $33^{\circ} \mathrm{C}$ as sporogony (the production of sporozoites which comprises dissemination and development of the parasite in the vector) cannot take place. Vectorial capacity of mosquitoes increases as temperature increases (optimal temperature between $22-30^{\circ} \mathrm{C}$ ). Mosquito lifespan increases with higher temperatures. Females 
increase blood meal frequency at higher temperatures. Aquatic life cycle of mosquitoes reduces from 20 to 7 days. Plasmodium species grow faster at higher temperatures (optimal between $27-30^{\circ} \mathrm{C}$ ). The minimum temperature required for development of Plasmodium vivax parasite in anopheline mosquitoes ranges from 14.5$16.5^{\circ} \mathrm{C}$, while for Plasmodium falciparum it ranges from $16.5-19^{\circ} \mathrm{C}$. However, the best conditions for development of the malaria parasite are $20-30{ }^{\circ} \mathrm{C}$ temperature and $60 \%$ relative humidity (RH) (Bruce-Chwatt, 1980). Climatic conditions such as El Nino, Tsunami and Hurricane have been shown to enhance malarial transmission. Tsunami can result in shattered sewer lines, contaminated fresh water supply and overcrowded refugee camps create a breeding ground for mosquitoes and precipitate the malarial outbreak.

In India, the majority of malarial cases have been reported from the eastern and central parts of the country and from those states which have large forest and hilly areas. According to the annual report of National Vector Borne Disease Control Programme (2014-15), prevalence of malaria is highest in Orissa followed by Chhattisgarh and Jharkhand. The major vector for rural malaria in India is Anopheles culicifacies, found all over the country and breeds in clean ground water collections whereas in urban areas, malaria is mainly transmitted by Anopheles stephensi which breeds in man-made water tanks, wells, cisterns etc. and hence can maintain density for malaria transmission throughout the year. Unplanned urbanisation, industrialization, improper sewage and solid waste disposal, indiscriminate disposal of articles (tyres, containers, junk materials, cups etc.) provide breeding site for mosquitoes and thus contribute to the spread of malaria. By 2050s, the geographical range of malaria vectors is projected to shift away from central regions toward south-western coastal States
(Maharashtra, Kerala and Karnataka) and northern States. The duration of exposure (transmission window) is likely to widen in north and west India and shorten in south India (Vaghela and Mangal, 2017). Construction of hydroelectric dams, irrigation canals has also lead to increase in malaria transmission rate (Tadei et al., 1998).

\section{Leishmaniosis}

It is a neglected tropical disease. Mostly people belonging to poor socio-economic group are affected. Leishmania parasites are known to be transmitted by Phlebotomine spp. The disease is endemic in warmer parts of the world covering almost 98 countries around the globe. It is estimated that 0.9 to 1.7 million new cases (0.2-0.4 million cases of visceral leishmaniosis and 0.7 million to 1.3 million cases of cutaneous leishmaniosis) and nearly 20,000 to 30,000 deaths occur annually (Steverding, 2017).

In 2017, more than $95 \%$ of new cases of visceral leishmaniosis (VL/kala-azar) have been reported from 10 countries: Bangladesh, Brazil, China, Ethiopia, India, Kenya, Nepal, Somalia, South Sudan and Sudan. The transmission of VL and its epidemiology is directly and indirectly affected by the climate. Climate directly affects the growth of sandfly and the distribution of VL disease. Since the sandflies require high temperature and sufficient moisture for their development but in cold climatic conditions their prevalence is limited because of limited growth. Small fluctuations in temperature can have a profound effect on the developmental cycle of Leishmania promastigotes in sandflies, which allows transmission of the parasite in nonendemic areas also. However, heavy rainfall on one hand can limit flight activity, limit resting site availability for adult sand flies and kill immature stages while on the other hand, flooding may aid to spread the vector and its 
larvae to distant and non-infected areas also. Climate also has indirect impacts on disease transmission by vector through various ways:

Changes in temperature, rainfall and humidity may have strong effects on the reservoir hosts by altering their distribution and influencing their survival and population sizes.

By influencing the local vegetation which serves as resting sites and sugar source for the Phlebotomine flies.

Transmission of VL can occur during famine, drought and flood which lead to huge displacement and migration of people and above all poor nutrition could compromise their immunity.

Recent studies have highlighted the spread of canine leishmaniosis: In South America as far south upto Northern Argentina (Salomon et al., 2008); from Southern to Northern Italy (Otranto et al., 2009a); from Northern to Southern Brazil ((Tomaz Soccol et al., 2009). This spread is due to the movement of the Phlebotomine vectors into previously noninfected areas, thus increasing the prevalence of leishmaniosis in human populations.

Global warming could prompt the establishment of canine leishmaniosis in areas such as the United Kingdom, where the vectors are currently absent, but where Leishmania infantum infected dogs that had travelled to endemic areas are present (Shaw et al., 2009).

According to Gonzalez et al., (2010), leishmaniosis is expanding to northern United States from Mexico and Texas where it is considered endemic, primarily due to the increase in the niches of the sandflies, dog importation and the increase in human migration and/or travel in the recent years. In the Amazon region, human populations accompanied by their infected dogs have immigrated, serving to increase the prevalence of leishmaniosis.

Cutaneous leishmaniosis (CL) mostly affects the population of America, the Mediterranean basin, the Middle East and Central Asia from where $95 \%$ of the cases have been reported. In 2017 new CL cases have occurred in Afghanistan, Algeria, Brazil, Colombia, Iran, Iraq and Syrian Arab Republic (Steverding, 2017).

In India, according to the Accelerated Plan for Kala-azar Elimination (2017) under directorate of National Vector-Borne Disease Control Programme, kala-azar is endemic in 54 districts (33 districts of Bihar, 4 districts of Jharkhand, 11 districts of West Bengal and 6 districts of eastern U.P) and it is estimated that 129 million population is at risk in these states. However few sporadic cases have also been reported from Gujarat, Tamil-Nadu, Kerala, Uttar Pradesh, Himachal Pradesh and Jammu and Kashmir. In India, the disease is transmitted in areas with a heavy annual rainfall, with mean humidity above $70 \%$ and a temperature range of $15-38^{\circ} \mathrm{C}$, abundant vegetation, subsoil water and alluvial soil. The disease is common in rural areas where houses are constructed with mud walls and earthern floors and where livestock and humans dwell in close proximity. It has been speculated that western India has become a VL-free zone, but studies have shown that after about 20 years Gujarat State is again at risk of VL infection.

In India CL is endemic in the western desert area of Rajasthan and used to be confined to hot dry north-western regions, but few sporadic cases were also reported from Punjab, Delhi, Haryana and Gujarat. Since 2003, new foci of infection have been reported from various parts of India including South India (Kerala) which may be attributed 
to newly recognised reservoir areas of CL in South India (Kumaresan and Kumar, 2007).

\section{Chagas disease (american trypanosomiasis)}

Chagas disease affects more than 5.75 million people and 70.2 million individuals are at risk of infection in Latin America (WHO, 2015). Chagas disease occurs principally in the continental part of Latin America. In recent years it has been increasingly detected in the United States of America, Canada, many European and some Western Pacific countries. In the United States, 238,091 individuals could be infected with $T$. cruzi, causing a considerable disease burden (Manne-Goehler, 2016).

Changes in land use, deforestation and movement of human populations can also bring people into contact with potential wild triatomine vectors (Guhl et al., 2009) that might incidentally assume a primary role in $T$. cruzi transmission. In Central and South America, domestic and peridomestic animals such as dogs, cats, armadillos, opossums and rodents serve as host reservoirs for Triatoma.

It has been predicted that the Brazilian Amazon is at risk for Chagas disease becoming endemic due to the confluence of factors i.e. uncontrolled deforestation and colonization which alters the ecological balance between reservoir hosts and wild vectors and migration of infected human population and their domestic reservoir hosts.

Species distribution models (SDMs) based on machine-learning algorithms and Geographic Information Systems (GIS) have been used to predict areas of potential distribution of $T$. cruzi vectors (Garza et al., 2014). These analyses typically show that climatic factors significantly influence the potential geographic distributions of vector and reservoir species.
Additionally, temperature may have a particularly strong influence on the behaviour of triatomine species. For instance, temperatures exceeding $30^{\circ} \mathrm{C}$ tend to increase insect metabolism whereas low humidity cause insects to increase their feeding rate to avoid dehydration. In domestic life cycles when indoor temperatures increase, the insects may develop shorter life cycles and higher population densities. High temperatures can also speed up the development of T. cruzi in vectors. Expected distributional shifts of vector species due to climate change are likely to alter spatial patterns of risk of Chagas disease, presumably through northward expansion of high risk areas in North America.

\section{African trypanosomiosis}

Trypanosomiosis, commonly known as sleeping sickness, spread by tsetse flies, imposes a huge burden on African people and livestock. In 1998, an estimated 70,000 cases of human African trypanosomiosis was reported but in 2009 after continued control efforts, the number of cases reported dropped below 10,000 (9878).

This decline in number of cases has continued with only 997 new cases reported in 2018, the lowest level since last 80 years. But 65 million people are currently estimated to be at risk of infection in sub-Saharan Africa (WHO, 2019). T. b. gambiense is endemic in 24 countries of west and central Africa and causes more than $98 \%$ of reported cases of sleeping sickness. $T$. $b$. rhodesiense is endemic in 13 countries of eastern and southern Africa, representing less than $2 \%$ of reported cases (WHO, 2019).

Since the vector's life cycles are sensitive to climate so spatial distributions of the infection can be predicted using satellite-derived proxies for climate variables. The association 
between shifts in tsetse ranges and epidemic outbreaks of sleeping sickness is relevant because forecasted regional climate changes are likely to cause changes in the distribution of certain tsetse species and alter the suitability of the environment for the parasite. A study conducted by McDermott et al., (2002) demonstrated that with climate change the risk of animal trypanosomosis in most places in eastern Africa will generally contract and increase in human population.

Temperature has a strong influence on tsetse population dynamics and distribution. The length of the tsetse pupal development period decreases with increasing temperature, whereas larval production decreases above a certain threshold and both pupal and adult mortality increase with temperature (Terblanche et al., 2008).

In the African Sahel zone, tsese fly inhabit the river banks, move into drier areas during the rainy season and return to the forests during dry season, as it requires the protection of vegetation or forest.

However, deforestation also increases disease transmission because replacement of the forest by tall crops such as cocoa, coffee, oil palms and mangoes, provide comfortable habitats for tsetse colonization and so the population engaged in agriculture and animal husbandry are vulnerable to infection.

A disease transmission model based on combining the direct effects of temperature on vector ecology, vector biology and vector parasite interaction has been prepared to extrapolate the compounding effects of global warming on the epidemiology of African trypanosomiosis.

The model predicts that epidemics can occur when mean temperatures are between $20.7^{\circ} \mathrm{C}$ and $26.1^{\circ} \mathrm{C}$. It also predicts that $46-77$ million additional people may be at risk of exposure by 2090 and a large shift of up to 60 per cent in the geographical extent of the range (Moore et al., 2012).

\section{Fasciolosis}

Fasciolosis is an emerging/re-emerging parasitic disease in many countries which is related to climatic and environmental changes as well as human socioeconomic activities. Animal fasciolosis caused by either Fasciola hepatica or $F$. gigantica is a significant disease among sheep and cattle. It contributes to losses of over $\$ 2$ billion dollars per annum in the livestock industry in North and South America (Nyindo and Lukambagire, 2015).

The lymnaeids transmitting $F$. hepatica are amphibious, inhabit at high altitudes in colder conditions in small water bodies such as those for temporal collections (from field irrigation or seasonal rain). Lymnaeids responsible for $F$. gigantica transmission are more adapted to warmer conditions and prefer large and deeper water bodies rich in aquatic vegetation, such as those for permanent collections which includes canals for irrigation and water supply. Thus transmission foci of fasciolosis by $F$. hepatica are more related to seasonality than fasciolosis by $F$. gigantica.

Over the past two decades human fasciolosis has gained primary importance as the cases have been reported from more than 75 countries world-wide. It affects approximately 35-72 million people worldwide and over 180 million are at risk of infection in both developed and underdeveloped countries (Mc. Daniel et al., 2014).

The strong dependence of fasciolosis on weather factors indicate that climate change may have a marked influence on the future evolution of this disease. An increase of a few degrees in environmental temperatures may 
trigger the emergence of cercariae from snails and also accelerate the production of cercariae within snails. The net outcome of increasing temperature will thus be a greater number of cercarial infective stages (Mas Coma et al., 2009).

In hyperendemic, high altitude areas of the Andean countries, small increase of temperature due to warming and $\mathrm{El} \mathrm{Nino}$ Southern Oscillation phenomenon may lead to higher transmission and infection rates of fasciolosis and thus modify its present low, moderate and high risk areas distinguished by both climatic and RS-GIS mapping.

Increasing drought and floods associated with El Nino also influences fasciolosis epidemiology. Drought may modify the spatial, patchy fragmentation of fasciolosis foci and floods may facilitate lymnaeid survival and geographically expand their populations. The spread of fasciolosis is related to the large capacities of fasciolids to colonise and adapt to new environments as well as to new intermediate and definitive hosts.

At present, fasciolosis is emerging or reemerging in many regions of Latin America, Africa, Europe and Asia both at animal and human levels. Global warming has been noted as the cause of increased animal fasciolosis in U.K. and France (Mas-Coma et al., 2009) and the forecasting model predicts the risk of serious epidemics in Wales by 2050 (Fox et al., 2011).

\section{Dirofilariosis}

Dirofilariosis is a vector-borne parasitic infection mainly of dogs and cats and is caused by $D$. immitis and $D$. repens. It is considered to be a great hazard in tropical, subtropical and in some temperate countries. The transmission of Dirofilaria occurs by mosquito of the genera Anopheles, Aedes and Culex. Both Dirofilaria species are zoonotic; $D$. repens is the causative agent for subcutaneous dirofilariasis in Asia, and Sri Lanka is endemic for this zoonotic infection and cardiopulmonary dirofilariosis caused by Dirofilaria immitis is relatively less prevalent. Transmission of Dirofilaria infections are dependent upon the presence of sufficient numbers of infected, microfilaraemic dogs, susceptible mosquitoes and a suitable climate to permit extrinsic incubation of Dirofilaria in the mosquito intermediate host. Canine Dirofilariosis has been studied more extensively in Europe. Epidemiological studies carried out until 2001 and between 2002 and 2011 suggest an expansion of disease from the endemic southern European countries towards central and northern Europe (Morchon et al., 2012).

Factors influencing the spread of the disease include:-

a) Movement of infected animals

b) Introduction of new species of mosquitoes able to act as vectors

c) Climate change caused by global warming

d) Development of human activity in new areas

Temperature, precipitation and relative humidity are the three main factors that determine the abundance of mosquitoes and the prevalence of mosquito-borne Dirofilaria infection.

Due to climate change caused by global warming, vector population has more suitable conditions for its development, increasing the geographical distribution of vectors, the number of mosquitoes able to transmit the disease as well as suitable temperature allow expanding the risk season for the transmission of the disease by favouring the development of infectious larvae in the vector.

In recent years, cases of human dirofilariasis 
are increasingly reported in India. Cases of $D$. repens are most commonly reported, followed by $D$. immitis. In India, most of the cases have been reported from the States of Kerala, Coastal Karnataka and Maharashtra, whereas less number of cases has been reported from North India (Ghosh, 2015).

\section{Schistosomosis}

The infection is prevalent in tropical and subtropical areas, in poor communities without potable water and adequate sanitation. Urogenital schistosomosis is caused by Schistosoma haematobium and intestinal schistosomosis is caused by $S$. mansoni, $S$. japonicum and others. Schistosomosis accounts for more than 200,000 deaths per year in sub-Saharan Africa.

It is the second most prevalent parasitic disease in the world, only behind the malaria. Schistosomosis affects more than 250 milion people and another 700 million are at risk of infection (WHO, 2018).

The abundance of the parasite is in direct proportion to that of snail population. Abundance of snail is dependent on the type of vegetation in the habitat, seasonal rain variation and changes in water temperature and flow. Temperature, water body type, rainfall, water velocity and altitude have a significant effect on the Schistosoma life cycle and survival of the intermediate snail host (Fenwick et al., 2006).

Fresh water snails generally prefer stagnant or slow moving water. Irrigation and drainage canals cause an increase in water stress which may result in reduction of snail population. In addition, construction of dams and irrigation projects reduce the speed of fresh water current which help the fresh water population to flare up. Example: The resurgence of Scistosoma japonicum infection in past few years in China is due to the construction of three Gorges dam, recovery of the Dongting lake and major flooding events.

An increase in annual growing degree-day (AGDD) will alter the extent and level of schistosomosis transmission (Yang and Bergquist, 2018). In other terms, the number of parasite generations will increase by speeding up their development and by extending the current area where parasite larvae and intermediate host snail can proliferate. In addition, high temperatures lead to the absence of Bioamphalaria species from Coastal East Africa and consequent absence of $S$. mansoni transmission.

Prolonged drought periods for more than nine months can stop the transmission of schistosomosis at the foci, while drought periods lasting less than seven months can aid the transmission of the disease in other parts of the region due to maintenance of the larval stage.

\section{Babesiosis}

Species Distribution Modelling (SDM) predicts that increase in temperature could drastically affect the ecology and geographic distribution of Ixodes ricinus, a vector of Babesia microti in Eurasian region.

Climatic changes affect seasonal activity and feeding behavior of I. ricinus at different life stages. I. ricinus is vulnerable to drought, so global warming may negatively affect its survival in Southern Eurasia.

On the other hand, high temperature could lead to milder winter and extended spring and autumn seasons, making northern Eurasian region suitable for the species (Porretta et al., 2013). Dermacentor reticulatus, vector of Babesia canis is present in 2/3 of the French territory, has now been reported in Belgium, Netherlands, Germany, Czech Republic, Slovakia and in the area of Moscow due to 
favouring milder winters (Beugnet and Monfray, 2013). Thus, increases in the activity of ticks, increases the risk of transmitting pathogenic agents.

\section{Onchocerciosis (river blindness)}

Onchocerciosis is caused by the parasite, Onchocerca volvulus and is transmitted by the bite of the blackfly, spp. Simuliidae. In each of the areas in which it occurs, West, Central and East Africa, Ecuador, Guatemala and Mexico, it is transmitted by a different species of Simuliidae. In Nigeria, river blindness is most common along the main river valleys. In the plateau state in Nigeria, the vectors breed during the wet season and peak biting density occurs at the height of the rainy season, with more infective parasites at the beginning and end of rain (Patz et al., 2000). The development time of eggs, larvae and pupae of Simulium spp. and of O. volvulus larvae, within the adult females of the vectors, decrease with increasing temperatures.

At and above $25^{\circ} \mathrm{C}$, the parasite could reach its infective stage in less than 7 days. It is predicted that fly number in Liberia and Ghana would peak at air temperature of $29^{\circ} \mathrm{C}$ and $34^{\circ} \mathrm{C}$ respectively. Small temperature increase (less than $2^{\circ} \mathrm{C}$ ) will lead to changes in the geographical distribution of some Simulium species (Cheke et al., 2015).

Table.1 (Hunter, 2003)

\begin{tabular}{|c|c|c|}
\hline Disease & Pathogen & Vector \\
\hline Malaria & $\begin{array}{l}\text { Plasmodium falciparum, } P \text {. vivax, } P \text {. } \\
\text { ovale, } P \text {. malariae }\end{array}$ & Anopheles spp.(Mosquitoes) \\
\hline Leishmaniosis * & Leishmania spp. & $\begin{array}{l}\text { Lutzomyia \& Phlebotomus } \\
\text { spp. (Sandflies) }\end{array}$ \\
\hline $\begin{array}{l}\text { African } \\
\text { Trypanosomiosis* }\end{array}$ & $\begin{array}{l}\text { Trypanosoma brucei gambiense, } \\
\text { T. b. rhodesiense }\end{array}$ & $\begin{array}{l}\text { Glossina spp. } \\
\text { (tsetse fly) }\end{array}$ \\
\hline Chagas disease * & Trypanosoma cruzi & Triatomine spp. \\
\hline Babesiosis & Babesia microti, B. divergens, & Ixodid tick \\
\hline Lymphatic filariasis* & Wuchereria bancrofti, Brugia malayi & Mosquito \\
\hline Onchocerciosis* & Onchocerca volvulus & Black flies \\
\hline Loaiasis & Loa loa & Tabanid flies \\
\hline Heart worm & Dirofilaria immitis, D. repens & Mosquitoes \\
\hline
\end{tabular}

* WHO neglected tropical disease

\section{Lymphatic filariasis (Elephantiasis)}

Lymphatic filariasis affects an estimated 120 million people in tropical and subtropical areas of the world. Endemic foci are found in sub-Saharan Africa, Egypt, southern Asia, the north-eastern coast of Brazil, Guyana, Haiti and the Dominian Republic. 90\% of lymphatic filariasis is caused by Wuchereria bancrofti (transmitted by Culex, Anopheles and Aedes spp.) and the remainder by Brugia spp. (transmitted by Mansonia spp.). WHO developed a new strategy and initiated a global program for the elimination of lymphatic filariasis as a public health problem by the year 2020 .

In the Orient, rice cultivation and flooding are associated with increased prevalence of filariasis and in the Nile delta, changes in soil moisture have preceded changes in prevalence of Bancroftian filariasis. 
In India, standing water polluted by faeces of domestic animals provide mosquito breeding grounds and wandering pigs and cows that destroy the banks of unlined drains create shallow habitats for mosquito larvae.

In India, the disease is reported to be endemic in 255 districts of 21 states and UTs. The population of about 650 million in these districts is at risk of lymphatic filariasis.

Warming of the climate system is unequivocal. Continued GHG emissions at or above current rates would cause further warming and induce many changes in the global climate system during the 21 st century that would very likely be larger than those observed during the 20th century.

Climate change will increase the impact of vector-borne diseases on human and animal health around the world. It also affects the distribution and incidence of VBD globally as evidenced by certain emerging and reemerging parasitic diseases. Impacts may include unanticipated emergence of new pathogen. Improved surveillance and monitoring using remote-sensing and geographic information system (GIS) is needed to derive mathematical models to predict the potential impacts of climate change on vector and vector-borne parasite.

Implementation of integrated vector control programme together with the multidisciplinary co-operation among workers in public health, veterinary health, ecology and social sciences holds out the best hope for responding and mitigating the effects of climate change.

\section{References}

Beugnet, F. and Chalvet-Monfray, K. 2013. Impact of climate change in the epidemiology of vector-borne diseases in domestic carnivores. Comparative
Immunology, Microbiology and Infectious Diseases, 36(6): 559-566.

Bruce-Chwat, L.J. 1980. Epidemiology of malaria-In book: Essential Malariology. William Heinemann Medical Books Ltd, London, Pp. 129-168.

Cheke, R.A., Basánez, M.G., Perry, M., White, M.T., Garms, R., Obuobie, E., Lamberton, P.H., Young, S., Osei-Atweneboana, M.Y., Intsiful, J. and Shen, M. 2015. Potential effects of warmer worms and vectors on onchocerciasis transmission in West Africa. Philosophical Transactions of the Royal Society B: Biological Sciences, 370(1665): 20130559.

Fenwick, A., Rollinson, D. and Southgate, V. 2006. Implementation of human schistosomiasis control: challenges and prospects. Advances Parasitology, 61:567-622.

Fox, N.J., White, P.C., McClean, C.J., Marion, G., Evans, A. and Hutchings, M.R. 2011. Predicting impacts of climate change on Fasciola hepatica risk. PLoS one, 6(1).

Garza, M., Arroyo, T.P.F., Casillas, E.A., Sanchez-Cordero, V., Rivaldi, C.L. and Sarkar, S. 2014. Projected future distributions of vectors of Trypanosoma cruzi in North America under climate change scenarios. PLoS neglected tropical diseases, 8(5).

Githeko, A.K., Lindsay, S.W., Confalonieri, U.E. and Patz, J.A. 2000. Climate change and vector-borne diseases: a regional analysis. Bulletin of the World Health Organization, 78(9):1136-1147.

González, C., Wang, O., Strutz, S.E., GonzálezSalazar, C., Sánchez-Cordero, V. and Sarkar, S. 2010. Climate change and risk of leishmaniasis in North America: predictions from ecological niche models of vector and reservoir species. PLoS Neglected Tropical Diseases, 4(1).

Ghosh, S.K., 2015. Human dirofilariasis: A fast emerging zoonosis in India. Indian Journal of Medical Microbiology, 33(4): 595.

Greer, A., Victoria, N and Fisman, D. 2008. Climate change and infectious diseases in North America: the road ahead. Canadian Medical Association Journal, 178(6):715- 
722.

Gubler, D. J. 2001. Climate variability and change in the United States: potential impacts on vector and rodent-borne diseases. Environmental Health Perspectives, 109(2):223-233.

Guhl, F., Pinto, N. and Aguilera, G. 2009. Sylvatic triatominae: a new challenge in vector control transmission. Memorias do Instituto Oswaldo Cruz, 104:71-75.

Hunter, P. R. 2003. Climate change and water borne and vector-borne diseases. Journal of Applied Microbiology, 94: 37S-46S.

IPCC. 2001. Prentice, I.C., Farquhar, G.D., Fasham, M.J.R., Goulden, M.L., Heimann, M., Jaramillo, V.J., Kheshgi, H.S., Le Quéré, C., Scholes, R.J. and Wallace, D.W.R. Chapter 3: The Carbon Cycle and Atmospheric Carbon Dioxide Executive Summary, in IPCC TAR WG1, Pp. 185225.

IPCC. 2007. Solomon, S., Qin, Dahe. and Manning, M. Working Group I: Contribution to the Intergovernmental Panel on Climate Change. Fourth Assessment Report: Climate change 2007: the physical science basis: summary for policymakers. Geneva.

IPCC. 2012. Field, C.B., Barros, V., Stocker, T.F., Qin, D., Dokken, D.J., Ebi, K.L., Mastrandrea, M.D., Mach, K.J., Plattner, G.K., Allen, S.K., Tignor, M. and Midgley, P.M. In: Managing the risks of extreme events and disasters to advance climate change adaptation. A special report of working groups I and II of the Intergovernmental Panel on Climate Change (IPCC). Cambridge University Press, Cambridge, UK, and New York, USA, Pp. 555-564.

Kumaresan, M. and Kumar, P. 2007. Letter to the Editor-Localized cutaneous leishmaniasis in South India: Successful treatment with ketoconazole. Indian Journal of Dermatology, Venereology and Leprology, 73(5): 361-362.

Manne-Goehler, J., Umeh, C.A., Montgomery, S.P. and Wirtz, V.J. 2016. Estimating the burden of Chagas disease in the United States. PLoS neglected tropical diseases, 10(11).
Mas-Coma, S., Valero, M.A. and Bargues, M.D. 2009. Climate change effects on trematodiases, with emphasis on zoonotic fascioliasis and schistosomiasis. Veterinary Parasitology, 163(4): 264-280.

McDaniel, C.J., Cardwell, D.M., Moeller, R.B. and Gray, G.C. 2014. Humans and cattle: a review of bovine zoonoses. Vector-Borne and Zoonotic Diseases, 14(1): 1-19.

McDermott, J.J., Kristjanson, P.M., Kruska, R.L., Reid, R.S., Robinson, T.P., Coleman, P.G., Jones, P.G. and Thornton, P.K. 2002. Effects of climate, human population and socio-economic changes on tsetsetransmitted trypanosomiasis to 2050. In The African Trypanosomes. Springer, Boston, MA. Pp. 25-38.

Moore, S., Shrestha, S., Tomlinson, K.W. and Vuong, H. 2012. Predicting the effect of climate change on African trypanosomiasis: integrating epidemiology with parasite and vector biology. Journal of the Royal Society Interface, 9(70): 817830.

Morchón, R., Carretón, E., González-Miguel, J. and Mellado-Hernández, I. 2012. Heartworm disease (Dirofilaria immitis) and their vectors in Europe-new distribution trends. Frontiers in Physiology, 3: 196.

NVBDCP (National Vector Borne Disease Control Programme). Annual report, Government of India, 2014-15. Available From: www.nvbdcp.gov.in/Doc/Annualreport-NVBDCP-2015

Nyindo, M. and Lukambagire, A.H. 2015. Fascioliasis: an ongoing zoonotic trematode infection. BioMed Research International, 2015.

Otranto, D., Capelli, G. and Genchi, C. 2009a. Changing distribution patterns of canine vector borne diseases in Italy: leishmaniosis vs. dirofilariosis. Parasites \& Vectors, 2 (1): S2.

Patz, J.A., Graczyk, T.K., Geller, N. and Vittor, A.Y. 2000. Effects of environmental change on emerging parasitic diseases. International Journal for Parasitology, 30(12): 1395-1405.

Porretta, D., Mastrantonio, V., Amendolia, S., Gaiarsa, S., Epis, S., Genchi, C. and 
Urbanelli, S. 2013. Effects of global changes on the climatic niche of the tick Ixodes ricinus inferred by species distribution modelling. Parasites \& Vectors, 6(1): 271.

Salomon, O., Sinagra, A., Nevot, M., Barberian, G., Paulin, P., Estevez, J., Riarte, A. and Estevez, J. 2008. First visceral leishmaniasis focus in Argentina. Memorias do Instituto Oswaldo Cruz, 103: 109111.

Shaw, S.E., Langton, D.A. and Hillman, T.J. 2009. Canine leishmaniosis in the United Kingdom: a zoonotic disease waiting for a vector? Veterinary Parasitology 163: 281285.

Steverding, D. 2017. The history of leishmaniasisA Review. Parasites and Vectors, 10:82.

Tadei, W.P., Thatcher, B.D., Santos, J.M., Scarpassa, V.M., Rodrigues, I.B. and Rafael, M.S. 1998. Ecologic observations on anopheline vectors of malaria in the Brazilian Amazon. The American Journal of Tropical Medicine and Hygiene, 59(2): 325-335.

Terblanche, J.S., Clusella-Trullas, S., Deere, J.A. and Chown, S.L. 2008. Thermal tolerance in a south-east African population of the tsetse fly Glossina pallidipes (Diptera, Glossinidae): implications for forecasting climate change impacts. Journal of Insect Physiology, 54(1): 114-127.

Tian, H., Lu, C., Ciais, P., Michalak, A.M., Canadell, J.G., Saikawa, E., Huntzinger, D.N., Gurney, K.R., Sitch, S., Zhang, B. and Yang, J. 2016. The terrestrial biosphere as a net source of greenhouse gases to the atmosphere. Nature, 531(7593): 225-228.

Tomaz Soccol, V., Castro, E.A., Navarro, I.T., de
Farias, M.R., de Souza, L.M., Carvalho, Y., Bispo, S., Membrive, N.A., Minozzo, J.C., Truppel, J., Bueno, W. and Luz, E. 2009. Allochthonous cases of canine visceral leishmaniasis in Paraná, Brazil: epidemiological implications. Brazilian Journal of Veterinary Parasitology, 18: 4651.

Vaghela, J.F. and Mangal, A. 2017. Climate Change and its effects on Vector Borne Diseases in India. International

Journal of Preventive, Curative and Community Medicine. 3(4): 4.

WHO (World Health Organization). Chagas disease in Latin America: an epidemiological update based on 2010 estimates. World Health OrganizationWeekly Epidemiological Record 2015, 90(6): 33-44.

WHO (World Health Organization). Schistosomiasis Fact Sheet of 20 February 2018. Available online: http://www.who.int/news-room/factsheets/detail/schistosomiasis (accessed on $3^{\text {rd }} \quad$ March 2020).

WHO (World Health Organization), World malaria report 2019. Regional and global trends in burden of malaria cases and deaths.

WHO (World Health Organization). WHO publishes new guidelines for the treatment of sleeping sickness. $8^{\text {th }}$ August 2019, Geneva.

Yang, G.J. and Bergquist, R. 2018. Potential impact of climate change on schistosomiasis: a global assessment attempt. Tropical Medicine and Infectious Disease, 3(4): 117.

\section{How to cite this article:}

Savita Bisen, Nidhi Rawat, Namrata Wahane and Pradeep Dubey. 2020. Implications of Climate Change on Vector and Vector-Borne Parasitic Diseases: A Bird's Eye View. Int.J.Curr.Microbiol.App.Sci. 9(03): 2185-2199. doi: https://doi.org/10.20546/ijcmas.2020.903.251 